\section{How to practice Brief Psychodynamic Psychotherapy}

\author{
Autores: Howard E. Book \\ Editorial: American Psychological \\ Association. $3^{\text {rd }}$ printing. \\ Washington, DC, 2003, \\ 181 páginas.
}

Con algún retraso hemos tomado contacto con este libro de Howard Book, notable en más de un aspecto. Por una parte, es un manual altamente didáctico del procedimiento desarrollado por Lester Luborsky y su equipo de la Universidad de Pensilvania desde hace más de cuarenta años del CCRT: método del Tema del Conflicto de Relación Nuclear. Por otra, relata detalladamente una psicoterapia exitosa llevada a cabo por el autor a la señora Benton durante 16 sesiones, conteniendo todos sus logros, dificultades, insuficiencias e incógnitas propios del complejo proceso curativo interpersonal. Además, combina con armonía la investigación empírica concreta con la práctica cotidiana en la variedad de caso único y paradigmático. Por último, despliega ante nuestra vista las peculiaridades inherentes a la persona y creatividad del terapeuta de modo que nos hace empatizar tanto con él como con los acontecimientos que se van sucediendo en forma vertiginosa - por decirlo así, somos protagonistas activos y privilegiados de la aventura psicoterapéutica, ya que Book nos hace partícipes permanentemente con preguntas y sugerencias.

Tres libros anteriores constituyen la base teórica y los fundamentos empíricos que avalan el CCRT y que provienen del famoso Proyecto $M$ enninger y de su continuador el Proyecto Penn: Lester Luborsky: Principles of Psychoanalytic Psychotherapy. A M anual for Supportive-Expressive Treatment, 1984, Lester Luborsky, Paul CritsChristoph, Jim Mintz y Arthur Auerbach: Wo will benefit from Psychotehrapy? Predicting therapeutic outcomes, 1988, y Lester Luborsky y Paul Crits-Christoph: Understanding Transference. The Core Conflictual Relationship Theme M ethod, 1997. Con ellos, Luborsky se colocó en el rango superior y aún aventajó con holgura a los investigadores que se preocuparon de la psicoterapia breve de orientación psicodinámica a partir de la década del 60, Peter Sifneos, Habib Davanloo, Hans Strupp, James M ann, David M alan, Jeffrey Binder. Si cotejamos estos trabajos con el texto de Book comprobamos que este ha seguido fielmente las conclusiones que se consiguieron con antelación y su aporte, además de constituirse en un confiable manual de instrucción y técnica, está más bien en demostrar cómo se pueden adaptar y utilizar en situaciones clínicas inesperadas e irrepetibles sin perder por tanto el sello personal del psicoterapeuta. De ahí que resulte particularmente atractivo para todos los principiantes en psicoterapia y para los clínicos que quieran seguir un método que posee una racionalidad clara y necesiten ayudar a sus clientes en pocas sesiones. No es lo que despectivamente se ha denominado un "libro de cocina", sino una guía que enseña a seguir pasos sistemáticamente proyectados y correctamente ejecutados. Evita caer en el error de muchas psicoterapias de duración indefinida en que, pasado algún tiempo, ya no se conoce hacia dónde se va ni qué se quiere cambiar o mejorar, amparados en la conocida frase de Freud de que el inconsciente es atemporal - 10 interminable corresponde, sin lugar a duda, a confusión interna o desorientación del psicoterapeuta antes que a la compleja dinamia de la psicopatología o al transcurso dificultoso de la interacción.

¿Cuáles son sus rasgos definitorios? Se busca establecer con fidelidad los principales episodios relacionales y entenderlos desde los deseos del sujeto (querer, anhelar, necesitar), las respuestas de los otros significativos a estos deseos (alejarse, enrabiarse, criticar, agredir, seducir) y, por último, los comportamientos subsecuentes del individuo a esas acciones (deprimirse, callarse aunque quedando enojado, inhibirse). De aquí se elabora el CCRT medido con un puntaje producto 
de la aplicación de una escala y que corresponde al destilado de los episodios relacionales 0 al modo de interactuar que produce más conflicto o patología emocional. Con posterioridad la psicoterapia se restringe al CCRT y se lo refiere tanto a las interacciones infantiles con sus padres como a las actuaciones con el terapeuta y con las personas actuales. El tratamiento es breve y se estructura en tres fases, y se circunscribe a 16 sesiones que se fijan de antemano y se mantiene inmodificable en ese número porque de esta forma se puede trabajar de antemano el proceso de término. Las sesiones semanales cara a cara son precedidas de una entrevista de evaluación que es determinante porque asegura si el enfermo es o no adecuado a la técnica: en el fondo, sujetos con un yo fuerte, capaces de relacionarse significativamente con los otros, motivados para el cambio interno antes que en las puras mejorías sintomáticas, con una sofisticación psicológica, y especialmente un problema que pueda ser reducido a un foco o conflicto central. Como se puede inferir, no se diferencia en estos últimos aspectos a las psicoterapias de M alan, M ann, Sifneos o Strupp. La principal peculiaridad radica en la simpleza y operacionalización estandarizada del foco: cómo son sus interacciones principales de acuerdo al deseo (W), respuesta de los otros (RO) y respuesta del yo (RS).

Como se ha insinuado hasta aquí, el método se adecua especialmente para la investigación empírica confiable y validable. Es lo que ha sucedido a escala internacional, especialmente por psicoterapeutas formados con Luborsky y su grupo, como es el caso del propio Book: Nancy Miller, Lester Luborsky, Jacques Barber y John Docherty: Psychodynamic Treatment Research. A Handbook for Clinical Practice, 1993. Aún en Chile se cuenta con algunos psicoterapeutas que han estado preocupados por emplear el CCRT y se está en espera de resultados que tengan un nivel de significación importante. Una primera impresión clínica es que resulta más sencillo de implementar y lograr un más alto consenso interjueces que las técnicas de Strupp y Binder, Sifneos, y Davanloo.
El entusiasmo que provoca la lectura no impide hacerse algunas preguntas. La primera: ¿estaremos en presencia de un procedimiento "psicodinámico", esto es, de orientación psicoanalítico? Hay dos características que hacen contestar en forma negativa 0, cuando menos, dejar en suspenso su fundamento teórico. En primer término, la ausencia del inconsciente propiamente tal; que Book hable de conflictos inconscientes quiere decir que estos son preconscientes de acuerdo a Freud: no hay proceso primario ni simbolismo ni nada que se parezca a la existencia de un lenguaje codificado. En segundo lugar, lo que se pregunta son por interacciones manifiestas entre el paciente y su medio y no por relaciones objetales internas entre el sujeto y sus imagos; de ahí que el modo de describir el intercambio terapéutico con la señora Benton es de acuerdo a una psicología cognitivista algo refinada con algunos componentes conductuales. La segunda: ies el psicoterapeuta alguien encargado de mostrar lo que el inconsciente del paciente va exhibiendo e interpretárselo para que este logre el insight mutativo? ¿O es alguien que dirige, manipula, sugiere con fuerza, impone, expone una doctrina, dice lo que es verdadero y falso ("eso está bien, bravo", "esta es realmente una de las metas de la terapia", "usted se está corriendo", "como le dije en la sesión anterior, lo mejor para usted es tener una oportunidad de hablar de estos asuntos", "pienso que lo que pasó es exactamente de lo que hemos estado hablando"? Tercera: si bien los criterios de selección son algo más flexibles que en los casos de Sifneos y Malan, el número de pacientes que son altamente perceptivos para su interioridad y capaces de tolerar las angustias que se van sucediendo mientras se van destruyendo las defensas son relativamente escasos, por lo que su utilización en los policlínicos es reducida 0 , cuando menos, bastante limitada en número.

Hacía tiempo que no leíamos un libro de psicoterapia tan estimulante clínicamente y entretenido en el mejor sentido del término. En menos de dos días se lo puede devorar porque de pronto uno se encuentra sumergido en un plot de suspenso con introducción, desarrollo y término. 
Las frases son simples, casi de un amateur del inglés, las repeticiones son incesantes, el nivel de abstracción es reducido: no importa, como lector uno necesita saber lo que va a acontecer y el desenlace final. No es poco en estos tiempos en que los textos y artículos de la especialidad rayan en la pedantería minuciosa del superespecialista que se refocila en el recién descubierto receptor cerebral - claro está, para mañana cambiar de nombre y declarar que lo que se había dicho en forma tan segura y definitiva no era sino el producto de un error estadístico en el análisis de los datos de la muestra de los cerebros de las ratas ¿0 de cobayos?
Gustavo Figueroa C. Editor Asociado Psiquiatría 